on. She describes the attacks as of a "stifling" character, as she cannot "move the chest to breathe," and the pain, which, not very severe at first, has gradually increased in severity, shoots into the left shoulder and down the left arm, and leaves the arm "cold and numb." You will remember that in the preceding case the patient said her left arm went "stone cold."

Before examining the patient's chest I pointed out that her attacks resembled those of angina pectoris, and that we might or might not discover the existence of some organic disease of the heart. After the most careful examination of the heart, in which one of my colleagues joined, no distinct cardiac murmur could be made out, but $I$ called attention to an alteration in the sounds over the aortic area, which $\mathbf{I}$ ventured to predict would become altered into murmurs. There was a slight roughening and prolongation of the first sound, and a marked accentuation of the second sound. Moreover, there appeared to me to be a loss of resonance on the right side of the sternum over a very limited area corresponding with the second and third cartilages and second interspace, which made me think of dilatation of the aorta or of the possible development in that situation of an aneurismal sac. A fortnight later the roughened first sound had become a distinct systolic murmur, and the accentuated second sound ended in a diastolic bruit, which was conducted downwards to the left of the mid-sternal region. As the paroxysmal attacks of pain had gradually increased in severity and in frequency, coming on now on the least exertion, and sometimes even when in bed, she was induced to come into the hospital. She had many attacks while in the hospital, but they were by no means of that agonising character sometimes seen. For the first three weeks she improved; the attacks were only momentary, and occurred with a good deal of irregularity; sometimes she would have two in a day; sometimes she would go a week without an attack. In the intervals she felt quite well. The attacks would often occur when she began to get up in the morning or after walking about a little in the ward. We tried iodide of potassium without benefit ; fiying blisters over the cardiac base relieved her somewhat. In the beginning of March her attacks became more frequent, and we gave her nitrite of amyl, but without any good result; then we tried nitro-glycerine in gradually increasing doses. We began with half a minim of the one per cent. solution, and increased it to three minims three times a day. Under this treatment she mended somewhat, and, feeling better at the end of March, she left the hospital by her own wish to visit some friends, and promised to return in a week, but the very day she was to have returned to the hospital she died suddenly, after bringing up a quantity of blood. Unfortunately we could not get a postmortem examination. I regret also that I had not then adopted the mode of exploring the cardiac sensibility, which I have applied in all the other cases I have brought before you, as well as in many other, into the particulars of which it would take up too much of our time to enter.

These last three cases, varying so greatly in severity and seriousness, appear to me to have many points in common. Their causal relationship is obvious. All three patients were young women in fairly good health, with no antecedents leading to cardiac disease, save that they were all of them engaged in the same kind of occupation, and they all three complained of the effects of carrying heavy trays unstairs. In the first and slightest of the cases the cardiac disturbance was undonbtedly aggravated by the abuse of tea. In all three, but especially in the last two, the symptoms complained of bore a striking likeness to one another. In neither of them, when first seen, was there any definite cardiac nurmur. Mry we not trace the varying effects or cardia: or vascular strain in each of them? I vislent and sustained nuscular efforts there is increased action of the cardiac muscle on the one haud, and ia creased resistance at the periphery from muscul ir compres. sion of the arterioles and cupllaries on the other. If the cardiac nusule is weak and ancmic, as a part of a general anmmi, the 1 the veutriaulur wall may yicld and become dilated, ind we mayg $g$ t palpit:tion and pain assuci ited with fatizue and mulumirion of the cardiac muccle, as was no doabt the ca-e wirh the list of these three, and probably to some ext.nt with the sesond. But suppo:ing the tone of the cariis mu*ele t's be grood, and its contractions sustained and vigurous, theis we should expect the stratin to be felt especid'ly in the first part of the anta, for it has to endure a twofold distending influence : it has to bear the increased impenus of the ventricular outllow, increased both in force and frequency, and the increased resistance in the peripheral vessels. Under these influences it may become the seat of chronic inflammatory changes (as we know it constantly does), which may extend to and involve the nerves of the cardiac plexus in relation with its walls, or a particular weak portion of its wall may yield and dilate and become the seat of an aneurismal sac, as was most likely the case in the third patient.

The causation, the localisation, the pathological relations, and the treatment of cardiac pain in the various cases which come before us in which this symptom occupies a prominent place, are well deserving of your careful and continued investigation. It is for this reason $I$ have brought the subject under your notice in some detail, and have described to you a method of exploring the sensibility of the cardiac and aortic regions, which promises to be as instructive as it is simple.

\section{CARCINOMA OF THE LEFT LUNG AND PLEURA. \\ WITH REMARKS.}

BY HENRY DAVY, M.B. LoND., M.R.C.P., PHYSICIAN TO THE DEVON AND EXETER MOSPITAL AND TO THE EXETER DISPENSARY.

I AM indebted to Mr. W. Brewster, then clinical assistant to the hospital, for many of these notes.

Philip S-, aged forty-three; admitted July 21 st, 1881. The patient has a good family history. He has worked in a sawpit, and has enjoyed good health up to the date of his present illnes. Eight months ago he bəgan to suffer from a troublesome cough, and after a time he became a patient under one of my colleagues in the Exeter Dispensary, by whom he was treated for phthisis. Subsequently he came under my own care, and, finding dulness and bronchial breathing at the left apex, I also considered it a case of phthisis for two or three weeks. Finding that his symptoms were hardly explicable on this view, I examined him more carefully, and persuaded him to enter the hospital under my care.

On admission. - The patient is a tall thin man, with an unhealthy-looking and emaciated appearance. His complexion is sallow, and there are verous stigmata about the cheek and nose. Lately he has lost flesh very rapidly, and he now has no appetite for any kind of food. There has been no hæemoptysis, but he has a very severe cough, especially at night, and he expecturates a good deal of phlegm. He complains of great pain in the left side, which, he says, sometimes causes him a "perfect agony." He cannot sleep at night, being kept awake partly by pain and partly by the cough. His bowels are constipated, but his tongue is clean and moist. His pulse is regular, but weak, and his temperature is about normal.

On examination, the heart, liver, and right side of the chest appear quite normal ; urine contains no albumen, specific gravity 1020. The left side of the chest hardly moves at all in respiration. It is almost universally dull both back and front, and there is a great feeling of resistance to the percussing fingers. Tactile vibration is eutirely lost, but no æogophonic sounds can any where be detected. Scarcely any air can be heard entering the lung either behind or in the axillary line, but in front, from the clavicle to the nipple-line, there is bronchial breathing. The intercostal spaces do not bulge-in fact, they appear flatter than on the right side, and by careful measurement it is found that the left side is rather more than an inch smaller than the right. Vocal resonance is everywhere diminished, and there is no bronuhophony or pectoriloquy at any part of the chest. The chest was punctured by an asuiratir in several places, but no fluid was found. The aspirating needle a seared to enter solid matter even when it was passed into the chest fo a couple of inches.

From this date (July 21\&4) patient steadily got worse. He was very restless at night, and the pain in the left side was very severe, in spite of all the usual tr-atment for this symptom. He could not sle-p at mint, and he lost both appetite and weight. His heart began to fail, and on Aug. 1lth the liver became enlarged and sume ascitis was 
detected. In deference to expressed opinions that there might be fluid in the chest, an aspirating needle was more than once used, but always with the result that no fluid was found. The ascites steadily increased, the measurement round the umbilicus being about one inch larger every day, while œdema of both legs and scrotum was also developed. His morning and evening temperature were about normal, but his pulse was often very weak and rapid. I dictated the following note :

Aug. 18th.-Patient is very restless, and is obliged to sit propped up in bed. His breathing is very quick and shallow, and he complains much of pain in his left side. There is cdema of the legs, more especially the left, and the scrotum and prepuce are also odematous. Liver dulness commences at the fifth rib, and extends almost down to the umbilicus. The enlargement is evidently due to congestion, is smooth and uniform, the liver edge being easily felt just above the umbilicus. As he sits up in bed the dulness due to the ascites commences three fingers' breadth below the umbilicus, while there is dulness in both flanks continuous with the liver dulness above. A distinct thrill can be felt from side to side through the fluid. Lungs : Behind on the right side the air does not enter well at the extreme base, and there is a slight amount of râles, probably due to œdema of the lung. The rest of the lung, both back and front, is normally resonant, and the breath sounds are puerile over it. At the extreme base of the left lung the percussion note is altered by intestines or stomach, but everywhere else the percussion note is absolutely dull. Very deep inspiration is accompanied at the extreme base by a coarse gurgling râle, higher up by a good many coarse râles, but over the greater part of this lung no air can be heard entering at all. Heart sounds appear normal, and the apex beat is hardly if at all displaced. From this date the patient became weaker and bis breathing more and more shallow, and on Ang. 3lst he died. Unfortunately I could not be present at the post-mortem, which was made by Dr. Blomfield, the house-surgeon. The lung was, however, kept for my inspection. I dissected out the root of the lung, and made sections of the tumour, whilst some very beautiful sections were also made for me by Mr. W. Brewster and by Dr. Heneage Gibbes, curator of the Anatomical Museum, King's College.

Necropsy. - Chest: On opening the thorax a considerable quantity of straw-coloured fluid escaped from both pleural cavities. On the right side the pleura appeared to be healthy, no thickening being found on any part eitber of the costal or visceral layer. The lung too was crepitant throughout, and, with the exception of some cedema, appeared quite normal; its weight was $1 \frac{3}{4} l b$. On the left side the lung was bound back in the vertebral groove, and was covered all over by a thick layer of a yellowish-white colour, which fixed it so tightly to the costal surface that it was removed with great difficulty. The whole of the costal pleura from base to apex was very greatly thickened, and was of the same yellowish-white colour as the pleura over the lung. In some parts the thickness of the costal pleura was two inches, and in no place was it less than half an inch. When cut into it had a hard, fibrous feel. The space between this thickened pleura and the lung was filled with straw-coloured serum. On removing the lung and cutting into it, it was found to be covered all over with a tbickened pleura, from all parts of which the lung tissue itself was invaded by bands of a similar nature to the thickened pleura. In parts the lung tissue was entirely destroyed, this being especially trus it the apex, base, and in the neighbourhood of the root of the lung. In these situations the lung was completely solidified and airless, almost white, and cut with a fibrous feel. The parts contiguous to these were solidified and airless, but the black mottling of lung tissue could be recognised; while in some parts the lung was imperfectly crepitant. On dissecting out the root of the lung it was evident tbat the new growth was oldest and most advanced in this situation. Around the principal bronchus it was of considerable thickness. a large mass of it almost obliterating the bronchus embedding the bronchial glands, and spreading for some distance around the divisions of the bronchi in to the lungs. The bronchial glands were enlarged, but most of them could be recognised in the midst of the growth, by which they were often comparatively little invaded. Some, however, were much invaded by the growth, and one which contained a small mass of calcareous matter had very little glandular structure recognisable. In no part of the lung were any dilated bronchi or cavities to be fonnd. Weight of lung plus mass of new growth removed with it, 3lb. 14oz. Heart and paricardium: The pericardium con- tained some straw-coloured fluid, but no growth. The heart (left side) was normal; the right side was dilated, and the mus. cular walls slightly thickened. The abdomen contained a large quantity of inoffensive dirty-yellow-coloured fluid. The intestines were normal. The liver was large, smooth, and congested; no new growth anywhere in it. The kidneys were large, red, and congested, otherwise normal ; the spleen was healthy; the abdominal glands were not enlarged. The head was not examined. Parts of the lung and pleura were hardened in Müller's fluid, and the microscopic examination of the sections made proved that the new growth consisted of a large amount of fibrous stroma, with masses of cells in the interstices; and there was no doubt that it was a carcinoma. Remarlis. - The rarity of cases similar to the one above related must be very great, for I have not been able to find any other recorded in which the pbysical signs were at all so well marked. It is true that cases are described in which large patches of dulness over thickened pleura were found; but in this instance the dulness was over the whole left side of the chest, and to a superficial examination resembled that found with a large pleuritic effusion. That it was not an ordinary case of pleurisy was, however, clear from the date of admission, the "diminished size of the chest" and the "flattening of the intercostal spaces" making the diagnosis of fluid improbable even before the use of the aspirator proved that fluid was not present. Nor was the condition of the patient like that of a man who had recovered from an acute pleurisy with a much thickened pleura. The absolute dulness of the whole side of the chest, the almost complete absence of breath sounds, the great pain patient suffered, together with his rapid emaciation and general appearance, proved that the primary cause of his illness was much more grave. In fact these symptoms, together with the others I have described, indicated to my mind that he was probably suffering from malignant disease of the lung and pleura; and during the course of his illness I saw no reason for considering any other diagnosis more compatible with his symptoms. The alternative diagnosis seemed to be that of "cirrhosis" or "fibroid phthisis" of the lung with thicken. ing of the pleura, and there were several reasons for taking this view of the case. His dusty work in a sawpit was just that which might start the cirrhotic change, and this change limited (as it usually is) to one lung, with thickening of the pleura, have produced all the physical signs we have described; while the cause of his illness, with the failure of the heart, congestion of the liver, and ascites, was just that which ordinarily heralds the termination of advanced cases of cirrhosis of the lung. On the other hand, cirrhosis of the lung is very gradual in its onset, and very slow in its progress. The patient had enjoyed good health up to eight months previous to admission, and had performed laborious work up to that time without difficulty. It was very unlike cirrhosis of the lung to have increased so rapidly as in eight months to produce the physical signs I have described, especially as during this time the patient had been removed from all the causes by which the cirrhotic change in the lung would be kept up. These physical signs could only be produced by the most advanced cirrhosis of lung tissue, and that this should have begun almost suddenly and increased so rapidly was extremely unlikely. Nor would this pathological change have accounted for the pain I have described, and which I have said often amounted to great agony. A diagnosis of malignant disease of the left lung and pleura was therefore made and maintained from the first, and this diagnosis was completely verified by the post-mortem examination. The disease evidently commenced at the root of the lung, extending along both the visceral and costal layer of the pleura. Early in the case it apparently surrounded and almost obliterated the principal bronchus, and to this cause is probably due the collapse of the lung, which was found bound dnwn with carcinomatous pleura in the vertebral groove. The extent to which the lung itself had been invaded was very great, so that very little crepitant tissue was left. Considering the probable seat of origin of the carcinoma at the root of the lang, I was surprised at the absolute freedom of the right lung and pleura from any trace of the growtl, and it is also to be remarked that no secondary growths were discovered anywhere. As to treatment, seda. tives of all kinds, with digitalis and stimulants for the failure of the heart, were freely used, but without any good effect whatever.

YELLOW FEVER has broken out at Brownesville, Texas, and is spreading with alarming rapidity. 